$12-1-2014$

\title{
Comprehensive Management of the Paranasal Sinuses in Patients Undergoing Endoscopic Endonasal Skull Base Surgery.
}

\author{
Gurston G Nyquist, MD \\ Thomas Jefferson University \\ Marc R Rosen, MD \\ Thomas Jefferson University \\ Mark E. Friedel, MD \\ Thomas Jefferson University \\ D David Beahm, MD \\ Thomas Jefferson University \\ Eollow this and additional works at: https://jdc.jefferson.edu/otofp \\ Christopher J Farrell, MD

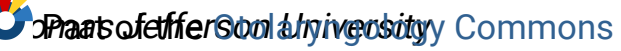 \\ Let us know how access to this document benefits you
}

See next page for additional authors

\section{Recommended Citation}

Nyquist, MD, Gurston G; Rosen, MD, Marc R; Friedel, MD, Mark E.; Beahm, MD, D David; Farrell, MD, Christopher J; and Evans, MD, James J., "Comprehensive Management of the Paranasal Sinuses in Patients Undergoing Endoscopic Endonasal Skull Base Surgery." (2014). Department of Otolaryngology - Head and Neck Surgery Faculty Papers. Paper 29.

https://jdc.jefferson.edu/otofp/29

This Article is brought to you for free and open access by the Jefferson Digital Commons. The Jefferson Digital Commons is a service of Thomas Jefferson University's Center for Teaching and Learning (CTL). The Commons is a showcase for Jefferson books and journals, peer-reviewed scholarly publications, unique historical collections from the University archives, and teaching tools. The Jefferson Digital Commons allows researchers and interested readers anywhere in the world to learn about and keep up to date with Jefferson scholarship. This article has been accepted for inclusion in Department of Otolaryngology - Head and Neck Surgery Faculty Papers by an authorized administrator of the Jefferson Digital Commons. For more information, please contact: JeffersonDigitalCommons@jefferson.edu. 
Authors

Gurston G Nyquist, MD; Marc R Rosen, MD; Mark E. Friedel, MD; D David Beahm, MD; Christopher J Farrell, MD; and James J. Evans, MD 


\title{
As submitted to:
}

\section{World Neurosurgery}

And later published as:

\section{Comprehensive Management of the Paranasal Sinuses in Patients Undergoing Endoscopic Endonasal Skull Base Surgery}

\author{
Volume 82, Issue 6, Supplement, pages: S54-S58
}

\section{December 2014}

\section{DOI: $10.1016 /$ j.wneu.2014.07.027}

Gurston G. Nyquist, MD, ${ }^{1}$ Marc R. Rosen, MD ${ }^{1}$ Mark E. Friedel, MD, MPH, ${ }^{1}$ D. David Beahm, $\mathrm{MD}^{1}$, Christopher J. Farrell, MD, ${ }^{2}$ James J. Evans, $\mathrm{MD}^{2}$

Departments of Otolaryngology-Head \& Neck Surgery ${ }^{1}$ and Neurological Surgery ${ }^{2}$, Thomas Jefferson University, Philadelphia, PA

Corresponding Author:

Gurston Nyquist, MD

925 Chestnut Street, $6^{\text {th }}$ Floor

Philadelphia, PA 19107

Phone: 215-955-6784

Fax: 215-923-4532

E-mail: gurston.nyquist@jefferson.edu

There was no funding, financial support, conflict of interest or duplication of material associated with this manuscript

Institutional Review Board approval was obtained through the Jefferson Medical College of Thomas Jefferson University

Key Words: Sinusitis, Endoscopic Skull Base Surgery, Transsphenoidal, Skull Base, Pituitary, Pituitary Adenoma 


\section{INTRODUCTION}

Evaluation and treatment of the paranasal sinuses plays in an integral role in the overall comprehensive management of patients with skull base lesions. Early endoscopic approaches to the skull base concentrated more on safety than preservation of nasal function. This resulted in significant sinonasal morbidity. Now that the safety of these procedures has been established, it is important to concentrate on preservation of sinonasal function. This requires careful evaluation of the sinuses pre-operatively, meticulous intra-operative dissection with preservation of sinonasal structures not directly involved with the pathology, and long-term follow-up postoperatively. The general goals include optimizing the sinuses pre-operatively to allow for a safe surgical corridor to enter the intracranial cavity and adhering to established principles in endoscopic sinus surgery for inflammatory disease. This consists of surgical techniques that promote mucosal preservation and mucociliary clearance, maintain ostia patency, minimize crusting, and prevent scar formation (11). In this review, we will discuss our current knowledge with regard to management of the sinuses in the setting of patients undergoing skull base surgery.

\section{PRE-OPERATIVE EVALUATION}

The otolaryngologist plays a pivotal role in the care of the paranasal sinuses. This begins with a careful pre-operative assessment that includes a history and physical evaluation. Previous sinus surgery or a history of sinusitis does not preclude an endonasal corridor to the skull base. Interestingly, the vast majority of patients with rhinosinusitis remain good candidates for an endoscopic endonasal approach to the skull base if patients are optimized pre-operatively.

Nasal endoscopy is essential pre-operatively to evaluate the sinonasal cavity and create a surgical plan. Information from the endoscopy will help determine the need for a nasal 
septoplasty and turbinate reduction, decide whether additional sinuses need to be surgically addressed for inflammatory disease, choose the best surgical corridor to the target pathology, and plan for the skull base reconstruction. Tackling these variables can improve the patient's quality of life with regard to nasal function while also treating the primary skull base pathology. Computed tomography (CT) is a second important diagnostic tool and can be used intraoperatively for image guidance. It provides the best information to evaluate the bony anatomy and is the gold standard radiologic technique to assess for rhinosinusitis while magnetic resonance imaging (MRI) is usually the best imaging modality to evaluate the primary lesion. We prefer both a pre-operative CT scan and MRI to best understand the disease process, assess for concurrent management of the paranasal sinuses, and have both modalities available for intraoperative image guidance.

Rhinosinusitis is a complex inflammatory disease that develops secondary to multiple etiologies that include infectious causes, allergic disease, immune dysfunction, cilia disorders and anatomic abnormalities to name a few. Optimizing patients with rhinosinsusitis preoperatively is critical. This may include the use of antibiotics, allergy medications, immunotherapy, irrigations of the nose, antihistamines, decongestants and steroids depending on the nature of the disease. The literature is sparse with data regarding management of patients with rhinosinusitis who will be undergoing an endoscopic endonasal skull base surgery. Similar to any elective surgery requiring general anesthesia, patients with acute rhinosinusitis ( $<4$ weeks) should be treated appropriately and surgery delayed until the patient is completely recovered. Patients with nasal polyps and eosinophilic mucin should be optimized perioperatively with steroids, similar to routine endoscopic sinus surgery as this decreases inflammatory swelling, makes the surgery less technically difficult, and improves post-operative outcomes with regard to 
polyp regrowth $(17,23)$. Patients with chronic rhinosinusitis (CRS) with or without polyps can be surgically addressed at the time of skull base surgery. A review of 250 consecutive cases since March 2009 in our database revealed 20 (8\%) patients who underwent concurrent surgery for CRS with or without nasal polyps and skull base pathologies. None of the patients developed an intracranial infection. Only one patient (5\%) continued to have rhinosinusitis and she required an additional endoscopic sinus surgery that is consistent with the need for revision endoscopic sinus surgery in the setting of CRS as reported in the literature (18). Two additional patients were staged and underwent endoscopic sinus surgery before having endonasal skull base surgery. One patient was found to have acute purulent sinusitis and another had a sinus fungal ball (sinus mycetoma) and it was decided to stage the procedures. Surgery is curative for a sinus mycetoma and once the sinus cavity has healed and the fungus cleared, then an endonasal approach to the skull base is possible. Both patients who were staged underwent successful endoscopic endonasal surgery for a pituitary macroadenoma without an infection or complication. No patients required a transcranial approach secondary to sinus inflammatory disease. In conclusion, for the vast majority of patients with chronic rhinosinusitis, the affected sinuses can be surgically addressed at the time of skull base surgery without an increased risk of infection.

\section{PERIOPERATIVE}

Meticulous attention to the sinonasal anatomy preserves function and translates to improved quality of life as compared to other approaches and allows patients to return to their baseline nasal function more quickly post-operativley $(1,15)$. The primary goals, like those for inflammatory disease, remain mucosal preservation techniques that maintain ostia patency and prevent scar formation. Mucosal stripping is avoided except in areas immediately around the 
skull base defect to allow the skull base reconstruction to adhere directly to the bony skull base. Permanent reconstructive materials that cover mucosa will likely result in mucocele formation and is thus avoided $(2,22)$. Otherwise, the mucosa should be preserved.

As a rule, we preserve all turbinates unless they are directly involved with the primary pathology. This helps preserve sinonasal function and also assures that these structures are available as a back-up plan in the future for cranial base repair if critically needed. A review of a 163 consecutive endoscopic transsphenoidal surgeries for multiple pathologies revealed that the middle turbinate could be gently lateralized and preserved in $98 \%$ of cases without compromising access (16). We gently medialize the middle turbinates at the conclusion of the case and routinely place a role of Gelfilm ${ }^{\mathrm{TM}}$ in the middle meatus to help maintain patency of the natural sinus drainage pathways and protect the skull base defect within the sphenoid sinus from inadvertent penetration like a nasogastric tube (9). (Figure 1) In addition, a very limited posterior septectomy is performed for routine transsphenoidal cases to limit crusting and anosmia. A flat sheet of Gelfilm ${ }^{\mathrm{TM}}$ is also placed between the nasal septum and inferior turbinates to reduce synechia. Excessive crusting from free mucosal edges increases the incidence of bleeding, obstruction, synechia formation, and the need for additional debridements $(7,10,11)$.

We described the use of a "button graft" for repair of skull base defects (14). Fascia lata is harvested and constructed so the inlay portion is at least $25 \%$ larger than the dural defect, and the onlay portion is just large enough to cover the dural defect. The two grafts are sutured together using a 4-0 Neurolon suture and placed with the inlay portion intradurally and the onlay portion extradurally (Figure 2). In addition, the use of vascularized flaps as part of the multilayer reconstruction not only decreases the rate of CSF leaks, but also decreases crusting and reduces 
healing time along the skull base $(8,10,15)$. Rapid and robust healing of the cranial base defect is particularly important in patients requiring post-operative radiation therapy. Harvest of the nasoseptal flap does not appear to adversely affect sinonasal quality of life compared to controls post-operatively. $(7,15)$.

For most routine transsphenoidal surgery, such as resection of a pituitary tumor, we prefer to perform a wide sphenoidotomy on the patient's right side and a partial sphenoidotomy on the left just superior to the natural ostium. This preserves the vascular pedicle on the left in case a nasoseptal flap is indicated in the future, minimizes post-operative crusting, and decreases the risk of delayed post-operative hemorrhage from a branch of the sphenopalatine artery. All patients receive 24-48 hours of antibiotics unless an extended course is indicated (3). We avoid the use of foley catheters to reinforce the skull base reconstruction as it may compromise blood flow to the nasoseptal flap, traumatize local tissue and cause patient discomfort. We also maintain the superior $1.5 \mathrm{~cm}$ of the nasal septum and superior portion of the superior turbinate to preserve olfactory function (8).

When these techniques are implemented the incidence of infection post-operatively is low. A review of 250 consecutive cases that consisted of multiple revision procedures after pituitary or other skull base surgeries demonstrated a $2 \%$ incidence of acute rhinosinusitis postoperatively as defined by the American Academy of Otolaryngology (19). Most of these patients were successfully managed medically. The incidence of meningitis or intracranial abscess was 0.7\%. Cappabianca et al. use similar techniques and report similar outcomes with regard to the rate of post-operative sinusitis and intracranial infections (5). 
The majority of patients are admitted to the intensive care unit following endoscopic skull base surgery. A face tent with mist humidification and saline gel or bacitracin applied to the nasal vestibule helps minimize crusting. Nasal cannulae are strictly avoided to reduce drying of the nasal mucosa and prevent the rare possibility that applied nasal airflow may cause tension pneumocephalus. Stool softeners are uniformly prescribed and patients are instructed to avoid nose blowing, heavy lifting or straining, and to sneeze with their mouth open. Patients are not routinely discharged home on prophylactic oral antibiotics unless an infection dictates further treatment.

Postoperative sinonasal care continues in the outpatient setting with the otolaryngologist one week post-operatively. Endoscopic debridement of the sinonasal cavity is performed and the cranial base is carefully inspected for a cerebrospinal fluid leak. Loose secretions and breakdown products from tissue sealants and hemostatic agents can be suctioned and removed. Crusting along the skull base reconstruction site is not instrumented until the scabs are no longer adherent to the skull base. Endoscopic debridements result in less crusting and synechia formation as compared to those who use saline alone (4). Patients begin saline irrigation after the one-week postoperative visit and return three weeks postoperatively for another debridement. The saline irrigation helps to clean debris from the nasal cavity, promote humidification, and dissolve packing materials such as Nasopore (Polyganics, Netherlands).

By the second post-operative visit, crusting along the skull base is significantly reduced after straightforward endoscopic transsphenoidal skull base surgery, especially if a limited posterior nasal septectomy is performed, the middle turbinates are intact, and a vascularized nasoseptal flap is implemented. In general, the more sinonasal tissue removed and the larger the skull base opening at the time of surgery, the greater the degree of crusting post-operatively 
$(7,11)$. However, this does not necessarily translate into the need for more frequent debridements, as this adds to patient discomfort and excessive mucosal trauma (12). Twice weekly debridements were found to negatively impact healing in patients undergoing surgery for strictly inflammatory disease. Thus, patients with more crusting generally require more humidification, frequent saline irrigation, and additional debridements separated by 1-4 week intervals.

If a sinus infection occurs then a culture directed choice of antibiotics is best. While amoxicillin is the first-line therapy for empiric treatment of acute bacterial rhinosinusitis, this may not be appropriate in skull base patients who were administered perioperative antibiotics and were recently hospitalized. A high dose amoxicillin-clavulanate, fluoroquinalone, macrolide or third generation cephalosporin may be a better choice. The literature is divided on the efficacy of topical antibiotic irrigation for acute rhinosinusitis as compared to saline irrigation in post sinus surgery patients $(6,13,20)$. The recommendation based on a systematic review of the literature suggests topical antibiotics should not be first line management but may be attempted in patients refractory to traditional oral antibiotics or in conjuction with oral antibiotics. This is consistent with our policy of how to treat post-operative rhinosinusitis or patients with excessive crusting. Crusting accompanied by mucoid secretions without significant mucosal inflammation is standard in skull base patients post-operatively and may not represent acute sinusitis (Figure 3). This is best addressed with humidification and saline irrigations with or without antibiotics. If symptoms persist for 3 months despite medical care or there is spread of infection beyond the confines of the paranasal sinuses then surgery may be indicated. 
In summary, the careful management of the paranasal sinuses is paramount to maintain healthy sinonasal function in patients undergoing endoscopic endonasal skull base surgery. Patients require proper pre-operative evaluation for rhinosinusitis and sinonasal obstruction that should be addressed at surgery. Those patients found to have sinusitis pre-operatively should be medically managed prior to surgery. Most cases of CRS can be surgically managed at the time of skull base surgery without an increased risk of intracranial infection or post-operative rhinosinusitis. The exception is patients with acute purulent rhinosinusitis refractory to medical care or fungal sinusitis who require staged surgery to address the sinuses before an endonasal skull base procedure. Rapid return of normal sinonasal function begins with meticulous mucosal and structural preservation techniques and is optimized by aggressive post-operative debridements and saline irrigation. 


\section{References}

1. Abergel A, Cavel O, Margalit N, Fliss DM, Gil Z. Comparison of quality of life after transnasal endoscopic vs open skull base tumor resection. Arch Otolaryngol Head Neck Surg. 138(2);142-147, 2012.

2. Bleier BS, Wang EW, Vandergrift WA $3^{\text {rd }}$, Schlosser RJ. Mucocele rate after endoscopic skull base reconstruction using vascularized pedicled flaps. Am J Rhinol Allergy. 25(3):186187, 2011.

3. Brown SM, Anand VK, Tabaee A, Schwartz TH. Role of perioperative antibiotics in endscopic skull base surgery. Laryngoscope. 117(9): 1528-1532, 2007.

4. Bugten V, Nordgard S, Steinvag S. The effects of debridement after endoscopic sinus surgery. Larngoscope 117:1528-32, 2007.

5. Cappabianca P, Cavallo LM, Colao A, Del Basso De Caro M, Esposito F, Cirillo S, Lombardi G, de Divitiis E. Endoscopic endonasal transsphenoidal approach: outcome analysis of 100 consecutive procedures. Minim Invasive Neurosurg. 45(4):293-200, 2002.

6. Desrosiers MY, Saias-Prato M. Treatment of chronic rhinosinusitis refractory to other treatments with topical antibiotic therapy delivered by means of a large particle nebulizer: results of a controlled trial. Otolaryn Head Neck Surg. 125:265-269, 2001.

7. De Almeida JR, Snyderman CH, Gardner PA, Carrau RL, Vescan AD. Nasal morbidity following endoscopic skull base surgery: a prospective cohort. Head Neck 33(4):547-551, 2011. 8. Hadad G, Bassagasteguy L, Carrau RL, Mataza JC, Kassam A, Snyderman CH, Mintz A. A novel reconstruction technique after endoscopic expanded endonasal approaches: vascular pedicle nasoseptal flap. Laryngoscope. 116(10):1882-6,2006. 
9. Hanna AS, Grindle CR, Patel AA, Rosen MR, Evans JJ. Inadvertent insertion of nasogastric tube into the brain stem and spinal cord after endoscopic skull base surgery. Am J Otolarnygol. 33(1):178-180, 2012.

10. Kassam AB, Prevedello DM, Carrau RL, Snyderman CH, Thomas A, Gardner P, Zanation A, Duz B, Stefko ST, Byers K, Horowitz MB. Endoscopic endonasal skull base surgery: analysis of complications in the authors' initial 800 patients. J Neurosurg 114(6): 544-68, 2011. 11. Kuhn FA, Citardi MJ. Advances in postoperative care following functional endoscopic sinus surgery. Otolaryngol Clin North Am 30:479-490, 1997.

12. Lee JY, Byun JY. Relationship between the frequency of postoperative debridement and patient discomfort, healing period, surgical outcomes, and compliance after endoscopic sinus surgery. Laryngoscope 118(10):1868-72, 2008.

13. Lim M, Citardi MJ, Leong JL. Topical antimicrobials in the management of chronic rhinosinusitis: asystem review. Am J Rhinol 22(4):381-389, 2008.

14. Luginbuhl AJ, Campbell PG, Evans J, Rosen M. Endoscopic repair of high-flow cranial base defects using a bilayer button. Laryngoscope 120(5);876-880, 2010.

15. McCoul Ed, Anand VK, Schwartz TH. Improvements in site-specific quality of life 6 months after endoscopic anterior skull base surgery: a prospective study. J Neurosurg. 117(3);498-506, 2012.

16. Nyquist GG, Anand VK, Brown S, Singh A, Tabaee A, Schwartz TH. Middle turbinate preservation in endscopic transsphenoidal surgery of the anterior skull base. Skull Base 20(5):343-347, 2010.

17. Poetker DM, Jakubowski LA, Lal D, Hwang PH, Wright ED, Smith TL. Oral corticosteroids in the management of adult chronic rhinosinusitis with and without nasal polyps: an evidence- 
based review with recommendations. Int Forum Allergy Rhinol, Aug 2012

doi:101002/alr.21072 (Epub ahead of print)

18. Ramadan HH. Surgical causes of failure in endoscopic sinus surgery. Laryngoscope 109;27-29, 1991.

19. Singh A, Schaberg MR, Nyquist GG, Anand VK. In: Schwartz TH, ed. Endoscopic Pituitary Surgery. New York: Thieme, 2011:321-327.

20. Soler ZM, Oyer Sl, Kern RC, Senior BA, Kountakis SE, Marple BF, Smith TL. Antimicrobials and chronic rhinosinusitis with or without polyposis in adults: an evidencedbased review with recommendations. Int Forum Allergy Rhinol June 2012, doi:10.1002/alr.21064. (Epub ahead of print)

21. Uren B, Psaltis A, Wormwald PJ. Nasal lavage with mupirocin for the treatment of surgicall recalcitrant chronic rhinosinusitis. Laryngoscope 118:1677-80, 2008.

22. Vaezeafshar R, Hwang PH, Harsh G, Turner JH. Mucocele formation under pedicled nasoseptal flap. Am J Otolaryngol. 33(5);634-636, 2012.

23. Wright ED, Agrawal S. Impact on perioperative systemic steroids on surgical outcomes in patients with chronic rhinosinusitis with polyposis: evaluation with the novel Perioperative Sinus Endoscopy (POSE) scoring system. Laryngoscope. 117(11 Pt Suppl 115), 1-28, 2011. 
Figure Legend

Figure 1. Endoscopic views of the same patient who underwent endoscopic endonasal transsphenoidal resection of a pituitary macroadenoma. A) Intraoperative view of the right nasal cavity with insertion of a rolled piece of Gelfilm into the middle meatus. B) Post operative view with a well healed nasal cavity and medialized middle turbinate (MT). C) Post-operative view of the sphenoidotomy ( $\mathrm{Sph}$ ) on the right side that serves as the working channel for the neurosurgeon. D) Post-operative view of a left sided limited sphenoidotomy for insertion of the

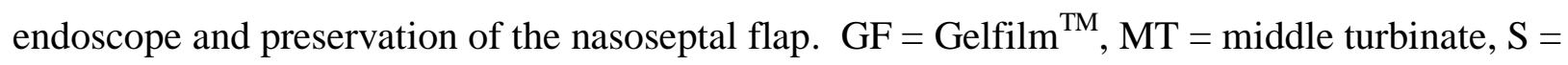
septum, $\mathrm{Sph}=$ spenoid sinus, $\mathrm{Ch}=$ choana

Figure 2. Demonstration of the Fascia Lata "Button Graft". A) $2 \mathrm{~cm}$ fascia lata button graft with the intradural and extradural secured with a mattress suture. B) Skull base defect after craniopharyngioma resection. C) Button graft positioned in an Inlay/Onlay fashion into the skull base defect. D) Button graft secured in position. E) Pedicled nasoseptal flap rotated into position over the button graft. SB = Skull Base, NSF = Nasoseptal Flap.

Figure3. A) Post-operative endoscopic view of left ethmoid cavity after concurrent skull base and sinus surgery demonstrating normal post-operative crusting. B) Acute sinusitis in the right nasal cavity after sinus surgery. $\mathrm{MT}=$ middle turbinate, $\mathrm{C}=$ crusting, $\mathrm{E}=$ ethmoid cavity, $\mathrm{S}=$ septum, $\mathrm{P}=$ purulent drainage. 